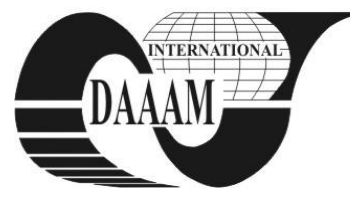

Annals of DAAAM for 2011 \& Proceedings of the 22nd International DAAAM Symposium, Volume 22, No. 1, ISSN 1726-9679 ISBN 978-3-901509-83-4, Editor B. Katalinic, Published by DAAAM International, Vienna, Austria, EU, 2011 Make Harmony between Technology and Nature, and Your Mind will Fly Free as a Bird Annals \& Proceedings of DAAAM International 2011

\title{
FINITE ELEMENT ANALYSIS USING PIEZOELECTRIC TRANSDUCERS MODELING
}

\author{
POPOVICI, D[orina]; JIGA, G[heorghe] - G[abriel] \& DINU, G[abriela]
}

\begin{abstract}
There are certain materials that generate electric potential or voltage when mechanical strain is applied to them or conversely when the voltage is applied to them, they tend to change the dimensions along certain plane. This effect is called as the piezoelectric effect. The piezoelectric transducers work on the principle of piezoelectric effect. When forces are applied to some materials along certain planes, they produce electric voltage. This electric voltage can be measured easily by the voltage measuring instruments, which can be used to measure the stress or force. In this paper the stress and deformation field of a cantilever beam subjected to a concentrated force at its extremity is analyzed, when electrical voltages are produced through a direct piezoelectric effect. In order to check the experimental results, a numerical code using triangular finite elements was performed. An eigen-frequency analysis is used to determine the eigen-frequencies and deformation modes of the analyzed structure.
\end{abstract}

Key words: piezoelectric transducers, artificial ceramics, smart materials, intelligent materials, stress values

\section{INTRODUCTION}

The conversion of electrical pulses to mechanical vibrations and the conversion of returned mechanical vibrations back into electrical energy is the basis for piezoelectric transducers. The active element is the heart of the transducer as it converts the electrical energy to mechanical energy, and vice versa. The active element is basically a piece of polarized material (i.e. some parts of the molecule are positively charged, while other parts of the molecule are negatively charged) with electrodes attached to two of its opposite faces. The piezoelectric effect occurs in materials where an externally applied elastic strain causes a change in electric polarization producing a charge and a voltage across the material. The most known piezoelectric material is quartz crystal. A lot of artificial ceramics as barium titanate, lead titanate, lead zirconate-titanate (PZT), potassium niobate, lithium niobate, and lithium tantalite have similar properties. In most applications the piezoelectric devices have a linear behavior.

\section{ELECTROMAGNETIC FIELD ANALYSIS USING A DISPLACEMENT TRANSDUCER}

The FEM analysis of a cantilever beam deformation producing electrical voltages through a direct piezoelectric effect is described in the following (Popovici et al, 2008). In order to simulate the structure a combined problem has been chosen: plane stress and piezo-plane stress. The geometry of the specimen is presented in figure 1 .

The domain $\mathrm{R} 1$ is an isotropic structural steel beam with a length $\mathrm{L}=550 \mathrm{~mm}$, width of $\mathrm{W}=50 \mathrm{~mm}$ and thickness $\mathrm{T}=5$ $\mathrm{mm}$. This material is defined in Library 1 of COMSOL numerical code. The domain R2 is a PZT $5 \mathrm{H}$ cell with a length $1=20 \mathrm{~mm}$, width $\mathrm{w}=50 \mathrm{~mm}$ and thickness $\mathrm{t}=0.5 \mathrm{~mm}$. For steel the following material constants have been used: $\mathrm{E}=2 \cdot 10^{5}$ [MPa], Poisson's ratio $v=0.33$ and density $\rho=7850 \mathrm{~kg} / \mathrm{m}^{3}$.

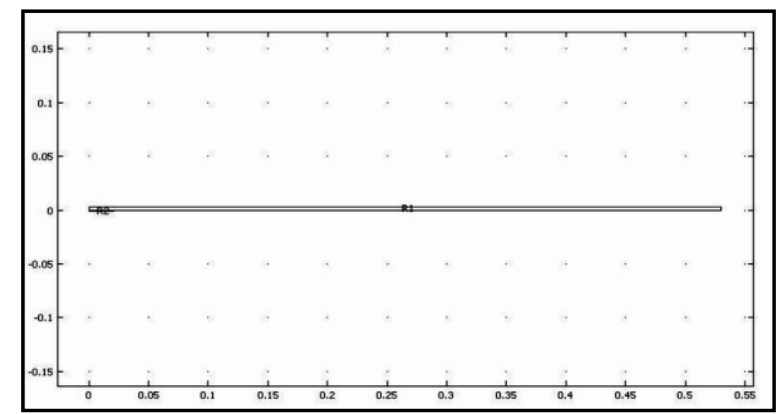

Fig.1. Geometry of the specimen

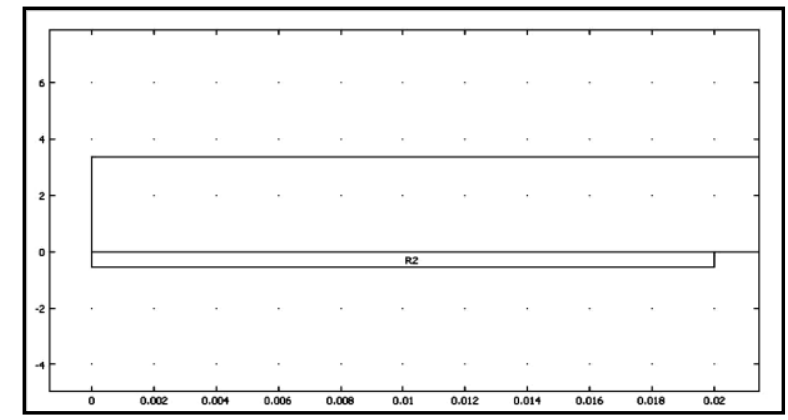

Fig.2. Zoom in the cell section

The PZT $-5 \mathrm{H}$ properties are: $\mathrm{c} 11=\mathrm{c} 22=126, \mathrm{c} 12=80.5$, $\mathrm{c} 13=\mathrm{c} 23=126, \mathrm{c} 33=117, \mathrm{c} 44=23.3, \mathrm{c} 55=\mathrm{c} 66=23[\mathrm{GPa}]$, $\mathrm{e} 51=\mathrm{e} 42=17, \mathrm{e} 13=\mathrm{e} 23=17, \mathrm{e} 33=23.3\left[\mathrm{C} / \mathrm{m}^{2}\right]$, the surface charge density respectively $\varepsilon_{11}=\varepsilon_{22}=1704, \varepsilon_{33}=1433$, the relative permittivity.

The boundary conditions result from the working conditions (figure 3). Concerning the mechanical aspect of the problem, a constraint on the left side of the beam and the PZT cell has been considered. The load was applied on the right end of the beam only on the $y$ direction. The meshed model contains 3516 triangular elements.

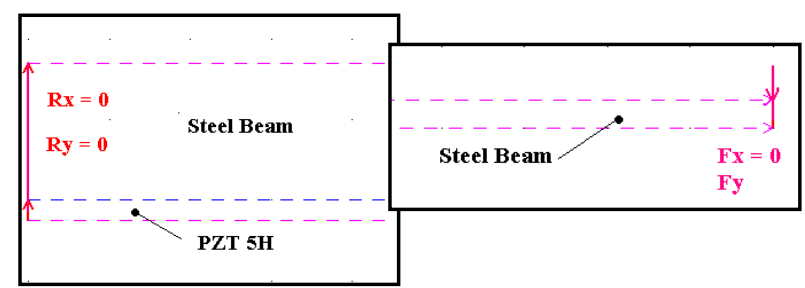

Fig. 3. The boundary conditions

\section{OBTAINED RESULTS}

Two basic analyses have been considered: static and eigen-frequency. 
At first, a static analysis has been achieved, where a uniform distributed load has been applied at the right end of the beam. This force had only a vertical component $\mathrm{p}_{\mathrm{y}}=10000$ $\mathrm{N} / \mathrm{m}$. The stationary direct linear solver UMFPACK has been used. In figure 4 is represented the displacements along the $y$ axis.

The maximum stress calculated with Von Mises criteria has been determined in the left side of the beam (in the vicinity of the clamping side) and was equal to 294 [MPa] whereas the minimum value in the right side of the beam was equal to 0,168 [MPa]. The voltage response of the PZT cell at different loads $\mathrm{p}_{\mathrm{y}} \in\{500,1000,2500,5000,7500,10000\}[\mathrm{N} / \mathrm{m}]$ has a linear variation as one can see in figure 5 .

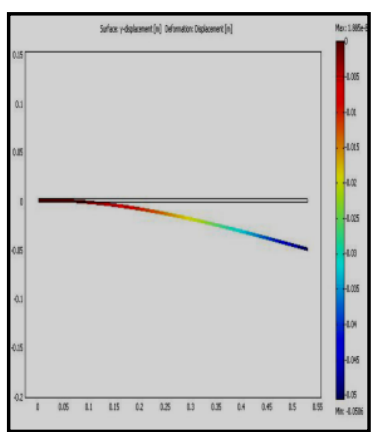

Fig.4. Beam displacement on $\mathrm{y}$ axis for $\mathrm{p}_{\mathrm{y}}=10000[\mathrm{~N} / \mathrm{m}]$

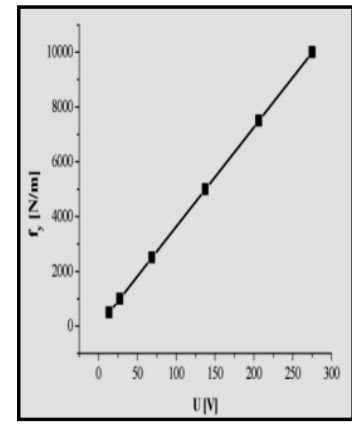

Fig.5. Linear dependence of $\mathrm{p}_{\mathrm{y}}=\mathrm{f}(\mathrm{U})$
For the same loads the displacement on y axis determined at the right side of the beam as well as the maximum stress values calculated with Von-Mises criterion are presented, as one can see in figures 6 and 7 .

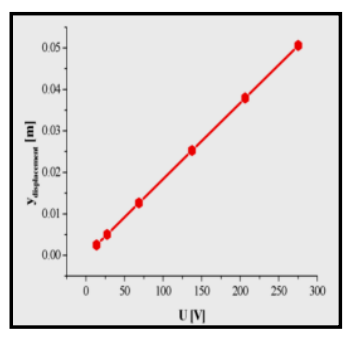

Fig. 6. Displacement of the right beam extremity

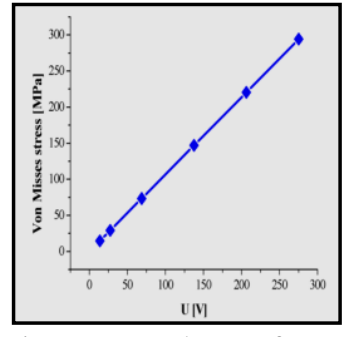

Fig. 7. Dependence of VonMises stresses $\mathrm{f}(\mathrm{U})$
The values of Von-Mises stresses and y-displacements are presented in Table 1.

\begin{tabular}{|c|c|c|c|}
\hline $\begin{array}{c}\boldsymbol{f}_{\boldsymbol{y}} \\
{[\mathbf{N} / \mathbf{m}]}\end{array}$ & $\begin{array}{c}\text { Von Mises } \\
\text { stresses } \\
{[\mathbf{M P a}]}\end{array}$ & $\begin{array}{c}\text { ydisplaceme } \\
\mathbf{n t}[\mathbf{m m}]\end{array}$ & $\boldsymbol{U}[\boldsymbol{V}]$ \\
\hline 500 & 14,71 & 2,53 & 13,75 \\
\hline 1000 & 29,42 & 5,06 & 27,51 \\
\hline 2500 & 73,55 & 12,65 & 68,77 \\
\hline 5000 & 147,1 & 25,30 & 137,55 \\
\hline 7500 & 220,6 & 37,95 & 206,33 \\
\hline 10000 & 294,2 & 50,61 & 275,10 \\
\hline
\end{tabular}

Tab. 1. Stress and displacement values in static analysis

An eigen-frequency analysis finds the eigen-frequencies and modes of deformation of the analyzed structure.

The eigen-frequencies $f$ in the structural mechanics field are related to the eigen-values $\lambda$ returned by the solvers through:

$$
\boldsymbol{f}=\frac{\sqrt{\lambda}}{2 \pi}
$$

The purpose of the eigen-frequency analysis is to find the six lowest eigen-frequencies and their corresponding shape modes. This model uses the same material, load and constraints as the static analysis. A direct system solver Umfpack was used and the results are presented in Table 2 .

\begin{tabular}{|l|l|l|l|l|l|}
\hline \multicolumn{1}{|c|}{$\mathrm{f}_{1}$} & \multicolumn{1}{|c|}{$\mathrm{f}_{2}$} & \multicolumn{1}{|c|}{$\mathrm{f}_{3}$} & \multicolumn{1}{|c|}{$\mathrm{f}_{4}$} & \multicolumn{1}{|c|}{$\mathrm{f}_{5}$} & \multicolumn{1}{c|}{$\mathrm{f}_{6}$} \\
\hline $\begin{array}{l}9,98 \\
\mathrm{~Hz}\end{array}$ & 64,48 & 174,73 & 341,91 & 564,31 & 841,75 \\
& $\mathrm{~Hz}$ & $\mathrm{~Hz}$ & $\mathrm{~Hz}$ & $\mathrm{~Hz}$ & $\mathrm{~Hz}$ \\
\hline
\end{tabular}

Tab. 2. The first six eigen-frequencies of the model

\section{CONCLUSIONS}

Piezo-electrics are materials that either output a voltage when subjected to a mechanical stress or exhibit a dimensional change when an electric field is applied. These two behaviors are referred to as the direct and indirect modes of operation respectively. Both modes of piezoelectric operation are currently being utilized in modem aerospace systems in such diverse applications as vibration cancellation and optical positioning. Because these materials have the ability to sense and respond to changes in their environment, they are often referred to as "smart" or "intelligent" materials.

The paper describes the FEM analysis (Morega et al, 2004) used for the study of a cantilever beam deformation when electrical voltages are produced through a direct piezoelectric effect. For the meshing of the model 3516 triangular elements have been used.

The numerical model approximated was in accordance with all experimental data. This method could be further developed in civil engineering, i.e. installations or big structures, where the determination of stress state cannot be easily achieved using the non-conventional methods.

\section{REFERENCES}

Cady, W. G. (1964), Piezoelectricity. An Introduction to the Theory and Applications of Electromechanical Phenomena in Crystals, Dover Publ., Vols. I and II, , New York

Hantila, F.I.; Preda, G. \& Vasiliu, M. (2000). Polarization Method for Static Fields, IEEE Transaction on Magnetics, Vol.36, No.4, Jul 2000, pp. 672-675, ISSN: 0018-9464

Makkonen, T. (2005). Numerical Simulations of Microacoustic Resonators and Filters, Doctoral Dissertation, Helsinki University of Technology, apr. 2005, ISBN 9512276364, pp. $1-75$

Morega, A.; Manescu, V. \& Paltanea, G. (2004). A FEM Static Model for a Piezoelectric Actuator Microgripper, Proceedings of the 4th International Workshop, Materials for Electrotechnics,, Bucharest, Romania, 2004, pp. 240 - p.245

Ostergaard, D. F. \& Pawlak, T. P. (1986). Three-Dimensional Finite Elements for Analyzing Piezoelectric Structures, 1986 IEEE Ultrasonics Symposium, pp. 639-644

Popovici, D., Constantinescu F., Maricaru, M., Hantila, F.I., Nitescu M. and Gheorghe A. (2008). Recent Advances in Modelling and Simulation, cap.25. "Modeling and Simulation of Piezoelectric Devices", International Journal of Advanced Robotic Systems Kirchengasse 43/3, A-1070 Vienna, Austria, EU

Wilson, O. B. (1989). Introduction to the theory and design of sonar transducers, Peninsula Publishing, ISBN: 978-0-93214622-9, Los Altos, California 